\title{
The Development of Continuing Medical Education in China
}

\author{
Duoyu Wu, Min Guo ${ }^{\circledR}$, Chenyun Xu* \\ Hainan General Hospital, Haikou, China \\ Email: ^g2002m@163.com
}

How to cite this paper: $\mathrm{Wu}, \mathrm{D}$. Y., Guo, M., \& Xu, C. Y. (2021). The Development of Continuing Medical Education in China. Creative Education, 12, 203-211. https://doi.org/10.4236/ce.2021.121015

Received: December 29, 2020

Accepted: January 23, 2021

Published: January 26, 2021

Copyright $\odot 2021$ by author(s) and Scientific Research Publishing Inc. This work is licensed under the Creative Commons Attribution International License (CC BY 4.0).

http://creativecommons.org/licenses/by/4.0/

\begin{abstract}
At present, the overall quality and diagnosis and treatment level of China's health personnel cannot meet the needs of social modernization and the protection of people's health. Especially with the further reform of medical education and medical service in China, new and higher requirements have been put forward for the quality of medical talents. Continuing medical education is not only an important part of medical education, but also the main way and important means of human resources development of health. At present, the competition of medical service environment is increasingly fierce, the competition between technology and equipment is no longer the only determinant of the competition between hospitals, and the cultivation and reserve of talents are increasingly significant. How to correctly position the management of continuing medical education, that is, the position of the management of continuing medical education in the development and construction of hospitals is related to the overall development of the hospital industry in the future. But at present, in the development process of continuing medical education, there is still a lack of a set of effective and perfect management system, which seriously restricts the development of continuing medical education. This paper takes the current situation of continuing medical education as the research entry point, analyzes the problems existing in its management in detail, and puts forward the corresponding solutions on this basis.
\end{abstract}

\section{Keywords}

Continuing Medicine, Education Management, Problem, Measures

\section{Introduction}

Medical Education is a Continuing Medical Education composed of school Medical Education, graduate Medical Education (after graduation) and Continuing Medical Education (CME) (Lang, 1993). Continuing medical education is a 
new type of education system that develops from traditional school education to lifelong education, which has been widely valued by countries all over the world (Gao et al., 2015; Teunissen \& Doman, 2008; Jia et al., 2014; Meng, 2010). The new theories, new knowledge, new technology and new methods of modern medical science are constantly emerging, and the cycle of knowledge updating is shortened. Only through continuing medical education can health technicians timely understand and master the latest medical theories and technologies, improve their own ability and quality, and better serve the clinical work. With the development of modern medical theory and technology, how to carry out continuing education for on-the-job medical staff is an urgent problem to be solved (Zhao \& Wang, 2016). In this regard, developed countries have taken the lead and accumulated a lot of successful experience (Liu \& Liang, 2013; Huang, 2011; Wang et al., 2015; Garattini et al., 2010; Wood, 1988; Starke, 2008; Tagawa, 2008; Kiyoshi \& Ryozo, 2007; Reeves, 2009; Page et al., 1995; Gaga et al., 2010; Peisah et al., 2007; Continuing Education Committee of Japan Medical Education Association, 2000). In developed countries, there are mainly two types of continuing medical education systems: one is the mandatory continuing medical education system, which is enforced mainly through legislation and system. Representatives of these countries are mainly France and the United States (Jia et al., 2014; Garattini et al., 2010; Gaga et al., 2010). The another is the non-mandatory continuing medical education system. In this system, although the country has a system and a plan, it mainly relies on medical staff to take the initiative to learn, and there are no hard and fast rules on continuing medical education. The main representatives of this kind of countries are the UK and Japan (Meng, 2010; Garattini et al., 2010; Wood, 1988; Starke, 2008; Tagawa, 2008; Kiyoshi \& Ryozo, 2007; Continuing Education Committee of Japan Medical Education Association, 2000). Throughout the development of continuing medical education in developed countries, although there are great differences in practices, there are some commonalities: first, they all recognize the necessity of continuing medical education; secondly, most of them have established specialized institutions to guide continuing medical education; thirdly, there are specific activity arrangements and guidance documents for medical continuing education (Huang, 2011; Wang et al., 2015). China's participation in global continuing education as a developing country began in 1979 when it sent representatives to attend the first World Conference on Continuing Engineering Education held in Mexico City (Sun, 2018). In the early 1980s, the concept of continuing medical education was introduced into China and the exploration of continuing medical education among health technicians began. In 1988, the Ministry of Health carried out the pilot work of continuing education in Zhejiang, Jilin, Changchun and other provinces (cities), and organized and drafted the interim Provisions on Continuing Education (Trial), the first legal document of continuing medical education in China. Since then, the pilot work has been further expanded to 11 provinces, municipalities and autonomous regions, including Hebei, Sichuan and Tianjin. 
Before the 1990s, continuing medical education just started in China, mainly based on academic qualifications. At that time, our country has not yet promulgated the national unified system of continuing medical education laws and regulations and the relevant country has yet to establish a consummate the organization to be responsible for the organization of continuing medical education and continuing medical education is in a state of disorder, independent health technical personnel training and continue to improve, due to differences in hospitals, health technicians, lack of equal opportunities to on-the-job continuing education, affected the physician knowledge updating and skills improvement. In 1996, the Ministry of Health established the Committee of Continuing Medical Education of the Ministry of Health, which formally proposed that the state should implement the system of continuing medical education for health technicians, and issued a series of regulations on continuing medical education, marking that the work of continuing medical education in China has been carried out in an all-round way. The promulgation and implementation of these documents have played a positive role in promoting the development and scientific management of China's continuing medical education. After more than 10 years of exploration, the work of continuing medical education has developed rapidly, and has been paid more and more attention by leaders at all levels and recognized by the majority of health technicians (Sun, 2017). At present, China's continuing medical education system has been relatively perfect, and the continuing medical education system with Chinese characteristics has been basically established (Ma et al., 2004; Yin \& Meng, 2016). Continuing medical education has become an important way and means for medical and health units to enhance their core competitiveness and improve the ability and quality of health technicians, and has played an important role in the construction of health personnel. After a large amount of manpower and material resources have been invested in continuing medical education, the policy makers, managers and the majority of health technicians urgently need to see the effects of continuing medical education, that is, the evidence of teacher training, discipline construction and improvement of medical level. The strengthening of continuing medical education provides a scientific management mode for medical education in China, guarantees the healthy development of hospital continuing medical education, and thus promotes the comprehensive development of hospital medical treatment, teaching and scientific research.

\section{Development Status of Continuing Medical Education in China}

Starting with the introduction of continuing medical education in China, after nearly 30 years of exploration practice, medical life-long education thought has been widely established, formed the national and local levels of continuing medical education committee, perfected the project examination and approval, credits granted, project management, base construction, assessment, file manage- 
ment and regulations of the distance education management, carried out, including national continuing medical education programs, multi-level, many forms of continuing medical education activities (Gilman et al., 2002). Continuing medical education in China has the characteristics of perfect organization, perfect rules and regulations, diversified forms of development, and covering all medical disciplines. Continuing medical education activities have been carried out in all provinces, municipalities and autonomous regions in China, playing an irreplaceable role in the progress of medical science, the continuous improvement of technical level and service capacity of professional health personnel, and the promotion of scientific development of health undertakings.

\subsection{There Is a Gap between Continuing Medical Education and Health Service Demand in China}

Although the system of continuing medical education in China has been established and gradually improved, there is still a big gap between it and the demands of the reform and development of health undertakings for continuing medical education and the people's ever-growing demand for health services, which is mainly manifested in: The development is unbalanced. Due to the limitations of economic and social development, health development level, cultural background, ideas and regional conditions, the work of continuing medical education varies greatly among regions, urban and rural areas, disciplines and units. Insufficient resources of continuing medical education coexist with low utilization efficiency. The resources of continuing medical education in China are not abundant, and they are mainly concentrated in the eastern coastal areas and large cities. The resources of continuing medical education at the grass-roots level, especially in rural and urban communities, are insufficient, and the utilization efficiency of the limited resources of continuing medical education is not high. The supervision and management of continuing medical education need to be strengthened. There is a lack of effective supervision and evaluation mechanism in the implementation of some continuing medical education programs, and the effects of educational programs are uneven. The form and content of continuing medical education activities are relatively simple (Liang, 2016). A considerable part of continuing medical education programs cannot well meet the needs of health professionals for multi-level, multi-form and individual learning, and fail to highlight the nature and characteristics of continuing medical education itself. The quality of continuing medical education needs to be improved. In some areas and units, continuing medical education is a mere formality and does not play a role in updating knowledge and technology. The theory of institutional change in the field of economics well explains that to promote the development of continuing medical education, a reasonable institutional guarantee must be provided. The state is the initiator of institutional supply and should provide institutional public products at the national level. All stakeholders in the field of continuing education should draw lessons from the theory of property rights to 
clarify their respective rights and obligations and provide more efficient institutional arrangements. Through the comparative study of the continuing medical education systems in BRICS countries, the following enlightenment can be obtained (Sun \& Zeng, 1999).

\subsection{Establish a Statutory Organization Management Body}

Continuing medical education is one of the components of the national strategy and belongs to the national function. We should learn from the experience of South Africa and India, legislate at the national level, establish relevant institutions, adhere to fairness and justice, and plan, coordinate and manage China's continuing medical education work (Cao \& Hu, 2002).

\subsection{Implement the Compulsory Continuing Medical Education System}

The implementation of the law on re-registration of medical practice is linked to the continuing medical education, which is also legally and systematically required by the profession. Health technicians must improve their health technical level through continuing medical education before they can re-register for practice. Fundamentally change the current passive learning status of health technicians from "I want to learn" to "I want to learn" and from passive learning to active learning. Effectively improve the level of health technicians in China, so as to promote the development of continuing medical education in China and ultimately improve the health level of the people (Wang, 2016).

\subsection{Integrating the Information Management Platform of Continuing Medical Education}

Continuing medical education at various levels and of relevant information, whether it is a continuing medical education program, or health technical personnel to participate in continuing medical education, integrating it into a platform, set up the national continuing medical education data system, the national and province, municipality directly under the central government, municipality level continuing medical education credits and hygienic and technical personnel to conduct a comprehensive project management (Hao, 2005).

\subsection{The Tuition Fee and Credit Management System Shall Be Implemented}

The tuition fee is mainly borne by the individual, and the credits are managed by the individual, which can effectively improve the sense of responsibility and enthusiasm of individual learning, thus making the students put forward higher requirements for the continuing medical education program and the supplier of the program, and forming an adverse mechanism for the content and teaching quality of the program. The systems of continuing medical education in BRICS countries have their own characteristics and similarities. China should constantly reform and improve the system of continuing medical education to promote 
the healthy development of continuing medical education. Should stick to the government, industry as the leading factor, which is based on enterprise, unit, medical institutions, health technical personnel individual learning as the main body, give full play to the individual active learning the enthusiasm, will continue medical education combined with personal professional development, improve the individual doctor's practice level, for the health development of our country and the national health service.

\section{Measures to Strengthen the Management of Continuing Medical Education}

\subsection{Update Ideas and Improve Understanding}

1) The hospital must be fully aware of the importance of continuing medical education, and to continue medical education Carry out scientific and unified planning and establish the development goal of continuing medical education; 2) Hospitals must be enlarged The input of funds provides financial guarantee for continuing medical education through multiple channels. 3) Must It is not only advantageous to accelerate the construction of key disciplines and characteristic specialties of hospitals and establish corresponding science and technology reward policies The innovation platform for medical personnel provides good hardware conditions for continuing medical education. 4) The hospital must It is necessary to strengthen the construction of the talent team in the hospital, train academic leaders, young key doctors and so on, and in a planned way The excellent talents in the school are sent to study and participate in academic exchanges at home and abroad, so as to form a good Learning atmosphere; 5) The hospital must intensify its publicity efforts to make all medical staff aware of the need to continue The importance of medical education and active participation in learning (Davis et al., 1995).

\subsection{Improve the Management System and Strengthen Management}

In the process of continuing medical education, a sound management system is the foundation to ensure its smooth development. Therefore, in view of the present situation of imperfect hospital management system of continuing medical education, it is necessary to combine with the hospital practically To develop a set of perfect, effective and feasible management system of continuing medical education. At the same time, in the process of management, it must be carried out in strict accordance with the relevant systems and regulations Earnestly implement and constantly strengthen its management.

\subsection{Establish a Sound Evaluation System for Continuing Medical Education}

Evaluation is a key link in continuing medical education, which directly affects the quality of education. At the same time, this link is also the weakest link in 
continuing medical education. Therefore, in response to this situation, we must: 1) Improve and perfect the credit system in continuing medical education, and attach importance to the issuance, verification, grading and management of credits Work alone. In the meantime, still can link credit system and medical personnel's employment, bonus, pair of credit Effective supervision and management of the source to prevent the occurrence of false credits, forged credits and other phenomena; 2) Establishment The evaluation system of individual, department and hospital continuing education, the content and quality of hospital continuing medical education, etc Conduct a comprehensive evaluation and link the evaluation results to performance; 3 ) The credits must embody the principles of "applying what you have learned". Reduce the secondary branch of continuing education, and appropriately increase the credit score in scientific research, thesis, business and other aspects, which fully reflects the "learning for application" and "principles" of continuing medical education.

\subsection{Enrich the Teaching Content of Continuing Medicine and Innovate Teaching Methods}

In view of the current situation that the contents of continuing medical education are outdated and backward, the process of continuing medical education is being implemented in the Chinese Academy of Sciences, the two levels of responsibility system should be implemented, and combined with the development of the discipline, work out a feasible continuation

Medical education content: On the basis of innovative educational content, we must take "what is missing" as the basic principle. Then, the current medical personnel education and long-term construction, clinical practice, academic research, social hot spots, etc. Combination of primary and secondary schools to meet the professional and career development needs of medical personnel. On the other hand, continuing medicine in education, it is necessary to innovate the educational means of the system, which is based on the traditional lecture education using the Internet as a form of distance education to meet the needs of medical personnel to learn anytime and anywhere.

\section{Suggestions and Measures}

To sum up, continuing medical education is an important part of medical education, which plays an important role in improving the professional ability of medical personnel and realizing the sustainable development of hospitals. However, at present, there are still some problems in the management of continuing medical education, and effective measures are taken to strengthen the management of continuing medical education and constantly improve its management level. Anyhow, continuing medical education must be incorporated into the institutionalization and standardization of the management system, from the aspect of leadership which attaches great importance to the continuing medical education, sets up the concept of lifelong learning, the continuing education of 
the attitude, for different levels, different regions, different professional health technicians, and flexibly uses a variety of continuing education. With this measure, the greatest degree enhances health technical personnel and learning ability and professional level of economic book, promotes departments to strengthen the quality management of continuing medical education activities; to strengthen the awareness of the importance of continuing education in all sectors of society; to enhance the importance of continuing medical education by leaders at all levels and the recognition of the majority of health technicians; to further promote the development of continuing medical education, and to promote the comprehensive development and progress of hospital medical treatment, teaching and scientific research.

\section{Foundation Project}

Hainan Health Commission Science and Technology Project (No. 20A200210).

\section{Conflicts of Interest}

The authors declare no conflicts of interest regarding the publication of this paper.

\section{References}

Cao, H. M., \& Hu, W. J. (2002). Evaluation and Discussion on the Effect of Continuing Medical Education. Jiangsu Health Services Management, 13, 28-31.

Continuing Education Committee of Japan Medical Education Association (2000). A Survey on Continuing Education of Active Physicians in Japan. Foreign Medical Sciences, Medical Education, 21, 25-28.

Davis, D. A., Thomson, M. A., Oxman, A. D. et al. (1995). Changing Physician Performance: A Systematic Review of the Effect of Continuing Medical Education Strategies. JAMA, 274, 700-705.

Gaga, M., Severin, T., \& Stevenson, R. (2010). Continuing Medical Education across Europe: The Role of EBAP and the ERS in Facing the Challenges of Life-Long Learning. European Respiratory Journal, 35, 721-722. https://doi.org/10.1183/09031936.00191209

Gao, J. H., Guo, H. T., Liu, G. et al. (2015). Application of PDCA Cycle in Skill Training and Assessment of Undergraduate Students in Clinical Practice Stage. Chinese Journal of Medical Education Exploration, 14, 509-512.

Garattini, L., Gritti, S., De Compadri, P. et al. (2010). Continuing Medical Education in Six European Countries: A Comparative Analysis. Health Policy, 94, 246-254. https://doi.org/10.1016/j.healthpol.2009.09.017

Gilman, S. C., Cullen, R. J., Leist, J. C., \& Craft, C. A. (2002). Domains-Based Outcomes Assessment of Continuing Medical Education: The VA's Model. Academic Medicine, 77, 810-817. https://doi.org/10.1097/00001888-200208000-00010

Hao, Z. S. (2005). Discussion on Strengthening Project Management of National and Provincial Continuing Medical Education. Continuing Medical Education, 19, 14-15.

Huang, R. Y. (2011). Comparative Study on the Training Mode of Medical Talents in European System-A Case Study of Britain, France and Germany. Medicine and Philosophy (Humanities and Social Medicine Edition), 32, 15-17.

Jia, W. Y., Jing, H. R., Zhao, G. Q. et al. (2014). Thoughts on Humanistic Education of Traditional Chinese Medicine in Standardized Training of Resident Physicians. Medi- 
cine and Philosophy, 35, 80-83.

Kiyoshi, K., \& Ryozo, N. (2007). Continuing Medical Education 1. Continuing Medical Education: Its Status in Japan. Nihon Naika Gakkai Zasshi. The Journal of the Japanese Society of Internal Medicine, 96, 2744-2750.

Lang, M. R. (1993). Comparison of Chinese and Foreign Medical Education. Shanghai: Shanghai Medical University Press.

Liang, S. (2016). Standardizing the Management of Continuing Medical Education to Promote the Sustainable Development of Hospitals. China Continuing Medical Education, $8,1-2$.

Liu, Y. C., \& Liang, Y. (2013). Analysis of French Medical Education System and Its Enlightenment. Journal of Jianghan University (Natural Science edition), 41, 107-112.

Ma, Z. T., Jing, S. Q., \& Yang, M. (2004). Overview of Continuing Medical Education in China. Continuing Education, 10, 25-26.

Meng, Q. (2010). Overview of Chinese and Foreign Resident/Specialist Training System (pp. 4-6). Beijing: China Union Medical University Press.

Page, G. G., Bates, J., Dyer, S. M. et al. (1995). Physician-Assessment and Physician Enhancement Programs in Canada. CMAJ, 153, 1723-1728.

Peisah, C., Adler, R. G., \& Williams, B. W. (2007). Australian Pathways and Solutions for Dealing with Older Impaired Doctors: A Prevention Model. Internal Medicine Journal, 37, 826-831. https://doi.org/10.1111/j.1445-5994.2007.01504.x

Reeves, S. (2009). An Overview of Continuing Interprofessional Education. Journal of Continuing Education in the Health Professions, 29, 142-146. https://doi.org/10.1002/chp.20026

Starke, I. (2008). Global Challenges in Continuing Medical Education and Continuing Professional Development in the United Kingdom. Journal of Continuing Education in the Health Professions, 28, S29-S30. https://doi.org/10.1002/chp.207

Sun, A. H., \& Zeng, Y. L. (1999). Effect Evaluation and Reform of Continuing Medical Education. Journal of Jiangxi Medical College, 39, 325-326.

Sun, S. X. (2018). Research on Existing Problems and Management Mode Reform of Continuing Medical Education. Human Resource Management, No. 4, 114-115.

Sun, Y., Shi, G. L., \& Huang, Y. L. (2017). Analysis and Management of Current Situation of Continuing Medical Education in Specialized Hospitals. Continuing Medical Education, 31, 3-5.

Tagawa, M. (2008). Physician Self-Directed Learning and Education. Kaohsiung Journal of Medical Sciences, 24, 380-385. https://doi.org/10.1016/S1607-551X(08)70136-0

Teunissen, P. W., \& Doman, T. (2008). Lifelong Learning at Work. BMJ, 336, 667-669. https://doi.org/10.1136/bmj.39434.601690.AD

Wang, L. L. (2016). Application of PDCA Cycle in Nurse Teaching Management of Neurosurgery. Continuing Medical Education, 30, 12-13.

Wang, X. G., Wu, R. Y., \& Chen, G. L. (2015). An Overview of the French System of Continuing Medical Education. Continuing Education, No. 5, 73-75.

Wood, J. (1988). Continuing Education in General Practice in the UK: A Review. Family Practice, 5, 62-67. https://doi.org/10.1093/fampra/5.1.62

Yin, C. B., \& Meng, K. (2016). Research Status Analysis of Standardized Training of Resident Physicians in China. China Hospital, 20, 26-28.

Zhao, Q. B., \& Wang, A. J. (2016). Evaluation of Standardized Training Effect of Geriatric Resident Physicians Based on PDCA Concept. Chinese Journal of Medical Education Exploration, 15, 576-579. 